
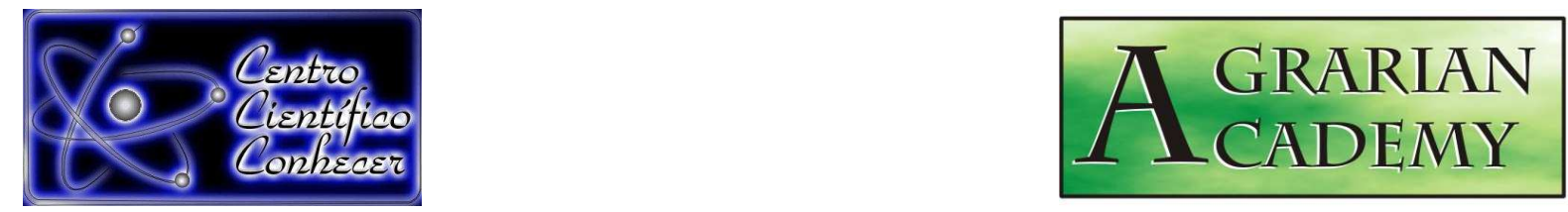

\title{
CARACTERIZAÇÃO FÍSICO-HÍDRICA DO SOLO EM DIFERENTES COBERTURAS EM FLORESTA PILOTO APÓS QUATRO ANOS DE IMPLANTAÇÃO
}

Rogério Rangel Rodrigues ${ }^{1}$, Jéferson Luiz Ferrari ${ }^{2}$, Wallace Luís de Lima ${ }^{3}$, Edvaldo Fialho dos Reis ${ }^{4}$, Mário Euclides Pechara da Costa Jaeggi ${ }^{5}$

${ }^{1}$ Doutorando em Recursos Hídricos em Sistemas Agrícolas pela Universidade Federal de Lavras, MG, Brasil. E-mail: rogeriorr7@hotmail.com;

${ }^{2}$ Professor do Departamento de Desenvolvimento Educacional do IFES, Campus de Alegre, ES, Brasil;

${ }^{3}$ Doutor em Agronomia (Ciências do Solo) - IFES, ES, Brasil;

${ }^{4}$ Professor do Departamento de Engenharia Rural - CCA-UFES, ES, Brasil;

${ }^{5}$ Mestrando em Produção Vegetal - UENF, RJ, Brasil

Recebido em: 16/11/2015 - Aprovado em: 10/12/2015 - Publicado em: 21/12/2015 DOI: http://dx.doi.org/10.18677/Agrarian_Academy_013

\begin{abstract}
RESUMO
A cobertura vegetal contribui para o aporte de carbono orgânico total, favorecendo melhorias físicas, químicas, biológicas e hídricas no solo. Portanto, objetivou-se com este trabalho a caracterização físico-hídrica do solo em diferentes coberturas em floresta piloto após quatro anos de implantação. O experimento foi conduzido em quatro áreas contíguas em floresta piloto. Os sistemas de uso e ocupação do solo foram: pastagem (Brachiaria brizantha), angico (Anadenanthera peregrina (L.) Speg), paricá (Schizolobium amazonicum (Huber) Ducke) e mata nativa. Foram utilizadas amostras deformadas, coletadas nas camadas de 0-20; 20-40; 40-60 e 60$80 \mathrm{~cm}$, com três repetições. As variáveis avaliadas foram: massa específica do solo, teor de carbono orgânico total, porosidade total e a retenção de água no solo. Foi realizada a correlação de Person para avaliar a influência da massa específica, carbono orgânico total, teor de argila, e porosidade total do solo na retenção de água na capacidade de campo e no ponto de murcha permanente. Os resultados demonstraram que o teor de carbono orgânico total e a massa específica do solo, até a camada de $60 \mathrm{~cm}$, foi inferiores na área de angico. No entanto, para a camada de 60-80 cm o teor de carbono orgânico total foi inferior na área de pastagem. A correlação de Person foi positiva para o teor de argila e porosidade total do solo, demonstrando a influência textural e estrutural no processo de retenção de água no solo.
\end{abstract}

PALAVRAS-CHAVE: anadenanthera peregrina (I.) speg. brachiaria brizantha. mata nativa. propriedades do solo. schizolobium amazonicum (huber) ducke. 


\title{
SOIL PHYSICAL CHARACTERISTICS IN DIFFERENT WATER COVERS IN FOREST PILOT AFTER FOUR YEARS OF DEPLOYMENT
}

\begin{abstract}
The vegetation contributes to the total organic carbon supply, favoring physical improvements, chemical, biological and water in the soil. Therefore, the aim of this work was the hydro-physical characterization of soil in different toppings on pilot forest after four years of implementation. The experiment was conducted in four contiguous areas in a pilot forest. The land use and occupation systems were: pasture (Brachiaria brizantha), angico (Anadenanthera peregrina (L.) Speg), paricá (Schizolobium amazonicum (Huber) Ducke) and native forest. Disturbed soil samples collected at 0-20 were used; 20-40; 40-60 and 60-80 cm, with three replications. The variables were: density of the soil, total organic carbon, total porosity and water retention in the soil. The correlation Person was performed to evaluate the influence of density, total organic carbon, clay content, and total soil porosity in water retention at field capacity and permanent wilting point. The results showed that the total organic carbon content and the density of the soil up to the depth of $60 \mathrm{~cm}$ was lower in angico area. However, for the layer of $60-80 \mathrm{~cm}$ of the total organic carbon content was lower in the pasture. The correlation was positive Person to clay content and the total porosity of the soil, demonstrating the influence on the textural and structural process water retention in the soil.
\end{abstract}

KEYWORDS: anadenanthera peregrina (I.) speg. brachiaria brizantha. native forest. schizolobium amazonicum (huber) ducke. soil properties.

\section{INTRODUÇÃO}

As diferentes coberturas vegetais têm grande influência na gênese e preservação do solo. Assim, os solos podem possuir diferenças estruturais que derivam da pedogênese, apresentando diferentes granulometrias, mineralogias e conteúdo de matéria orgânica, características estas que podem ser modificados pelo uso e cultivo do solo (CENTURION et al., 2004). E neste contexto, os estudos relacionados com a melhor forma de uso e manejo do solo poderão favorecer a escolha do método de manejo mais adequada para cada região.

De acordo com ROZANE et al. (2010), o manejo e as condições físicas do solo tenderão a um estado estável, o qual é dependente das condições edafoclimáticas e dos sistemas de manejo empregados. Segundo os mesmo autores, os diferentes sistemas de manejo empregados poderão resultar na preservação da matéria orgânica e do equilíbrio físico do solo, que poderão ser favoráveis ou não, à sua conservação e à produtividade das culturas.

Para BEUTLER et al. (2002) o manejo do solo também tem grande influência sobre a capacidade de retenção de água no solo, uma vez que interfere, positiva ou negativamente nas propriedades físicas, químicas e biológicas do solo. Além disso, de acordo com SILVA et al. (2012), a interferência negativa sobre as propriedades físicas e hídricas do solo influenciam os processos hidrológicos, incluindo a infiltração, a erosão, a redistribuição de umidade e o transporte de solutos no perfil do solo.

PORTELA et al. (2001), observaram que a diminuição da porosidade do solo sob cultivo de citros, influenciou negativamente a retenção de água no solo, quando comparado com cultivo de mandioca e mata. MACHADO et al. (2008) observaram efeito positivo da matéria orgânica sobre a maior retenção de água pelo solo. Contudo, segundo BEUTLER et al. (2002), dependendo das condições que regem o 
processo de retenção de água pelo solo, a contribuição da matéria orgânica pode não ser determinante para uma maior retenção de água.

Diversas pesquisas têm demonstrado os efeitos da cobertura vegetal sobre as propriedades físicas do solo (SILVA JUNIOR et al., 1995; GÓES et al, 2005; CHRISTOPHER \& LAL, 2007; LUCA et al., 2008). No entanto, a mata nativa tem sido referência para estudos de aporte de matéria orgânica do solo. Por isso, sistemas que assemelham a essas matas, como o reflorestamento para a preservação, tem obtido resultados satisfatórios no aporte de matéria orgânica do solo (BROWN \& LUGO, 1994).

Desta forma, objetivou-se com este trabalho fazer a caracterização físicohídrica do solo em diferentes coberturas em floresta piloto após quatro anos de implantação.

\section{MATERIAL E MÉTODOS}

O experimento foi conduzido em dezembro de 2013, em Floresta Piloto (implantada em janeiro de 2010), localizado no Município de Alegre, ES, segundo o sistema geodésico de referência WGS 84, nas coordenadas geográficas de 2045'45" S e 4127'40" O.

A região caracteriza-se por pertencer ao Bioma de Mata Atlântica composto por vegetação do tipo floresta tropical, dependente das características climáticas da região onde ocorre. De acordo com a classificação climática de Köppen o clima da região enquadra-se no tipo Awa (inverno seco e verão chuvoso), com precipitação média anual de $1.200 \mathrm{~mm}$ e temperatura média anual de 26을 $\mathrm{C}$. O solo da área experimental foi classificado como Latossolo Vermelho-Amarelo (EMBRAPA, 2013), situando-se numa área de relevo suave ondulado, a $148 \mathrm{~m}$ de altitude.

Antes da implantação da floresta piloto as áreas reflorestadas eram utilizadas como pastagem para caprinos. Para avaliar a cobertura de pastagem, foi utilizada uma área onde não houve o pegamento das mudas plantadas, sendo essa área em torno de $30 \mathrm{~m}^{2}$. Sendo assim, as áreas escolhidas para o estudo foram quatro áreas em diferentes coberturas vegetais: A1 - Área de pastagem, formada por Brachiaria brizantha, A2 - Área reflorestada com angico (Anadenanthera peregrina $L$ Speg), A3 - Área reflorestada com paricá (Schizolobium amazonicum Huber Ducke) e A4 Área de mata nativa (usada como referência).

Foram utilizadas amostras de solo deformadas, coletadas nas camadas de 020; 20-40; 40-60 e 60-80 cm, retirando-se, aproximadamente, $750 \mathrm{~cm}^{3}$ de solo por amostra. Em cada área avaliada foram realizadas três repetições, distanciadas cinco metros entre si. As variáveis físico-hídricas do solo determinadas foram: massa específica do solo, retenção de água no solo, granulometria, carbono orgânico total, porosidade total e água disponível no solo.

Foi feita a correlação de Pearson para verificar a influência do carbono orgânico total, da massa específica do solo e do teor de argila na retenção de água na capacidade de campo e no ponto de murcha permanente. Foi utilizado teste de média não-paramétrico, método de Kruskal-wallis, para avaliar a diferença estatística ao nível de $p<0,05$ de probabilidade, entre as variáveis avaliadas. As comparações foram feitas entre mesma camada de solo e entre as áreas avaliadas. 


\section{RESULTADOS E DISCUSSÃO}

Na Figura 1 é demonstrado o teste de média para o teor de carbono orgânico total para as quatro áreas avaliadas em diferentes camadas.

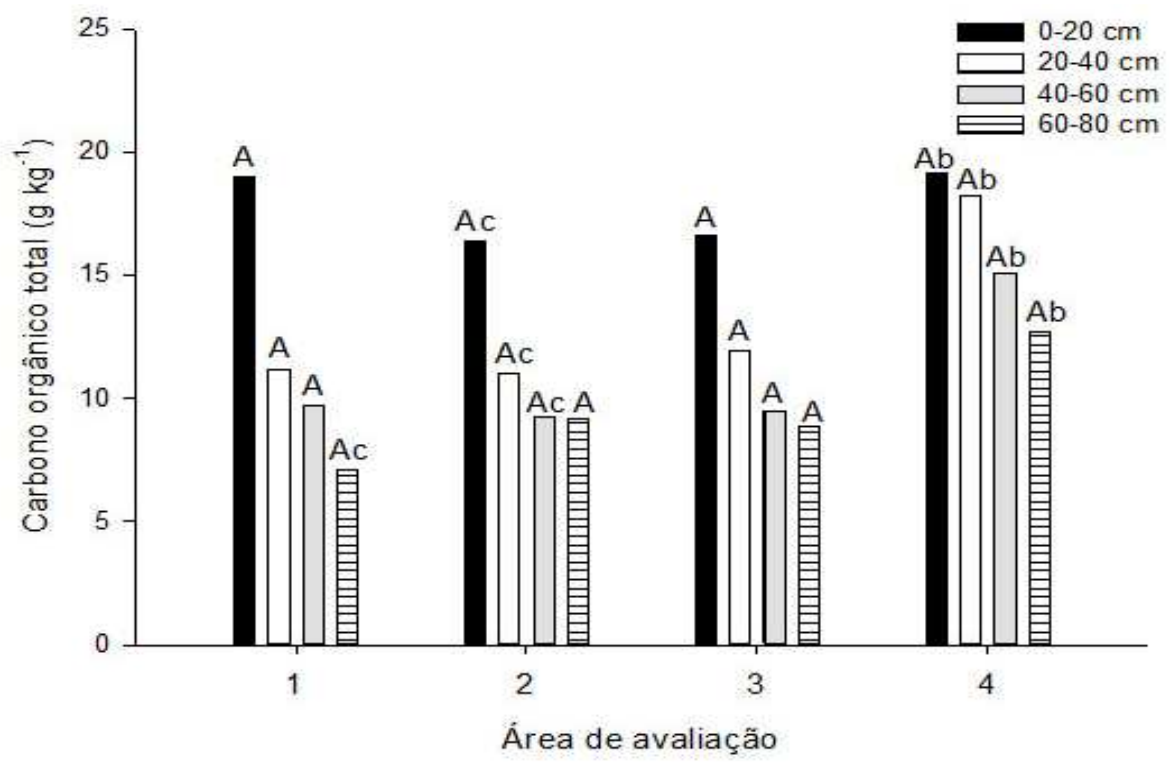

FIGURA 1. Carbono orgânico total para as quatro áreas avaliadas, sendo: 1 - pastagem; 2 - angico; 3 - paricá; e 4 - mata nativa.

Médias seguidas da mesma letra maiúscula e minúscula entre colunas e entre áreas não diferem entre si ao nível de $p<0,05$ de probabilidade pelo teste de Kruskalwallis.

Ao avaliar o teor de carbono orgânico total na camada de $0-20 \mathrm{~cm}$ para as quatro áreas, nota-se que houve diferença estatística apenas entre a área de angico (2) e de mata nativa (4), tendo a mata resultado superior à área de angico, obtendo média de $19,12 \mathrm{~g} \mathrm{~kg}^{-1}$ para mata e $16,41 \mathrm{~g} \mathrm{~kg}^{-1}$ para angico. A área de pastagem (1) e de paricá (3) não diferiram estatisticamente entre si e entre as demais áreas, obtendo valor médio de 18,96 e $16,63 \mathrm{~g} \mathrm{~kg}^{-1}$, respectivamente.

Da mesma forma, a camada de $20-40 \mathrm{~cm}$ foi estatisticamente diferente entre angico (2) e mata nativa (4), apresentando, respectivamente, valor médio de carbono orgânico total de 10,99 e 18,19 g kg-1. As demais áreas não apresentaram diferença estatística, obtendo valor médio de $11,20 \mathrm{~g} \mathrm{~kg}^{-1}$ para pastagem (1) e 11,91 $\mathrm{g} \mathrm{kg}^{-1}$ para paricá (3).

$\mathrm{Na}$ camada de 40-60 cm também houve diferença estatística apenas entre mata nativa (4) e angico (2), apresentando valor médio de carbono orgânico total de 15,09 e 9,26 g kg${ }^{-1}$, respectivamente. As áreas de pastagem (1) e paricá (3) não diferiram entre si e das demais, apresentando valor médio de 9,68 e 9,51 g kg-1, respectivamente.

Ao avaliar a camada de $60-80 \mathrm{~cm}$, nota-se que houve diferença estatística entre a área de mata nativa (4) e pastagem (1), apresentando valores médios de 12,71 e $7,11 \mathrm{~g} \mathrm{~kg}^{-1}$, respectivamente. Esse resultado diferiu dos demais cuja diferença estatística foi entre a área de mata nativa e angico. Esse resultado demonstra que, para essa camada de solo, a pastagem favoreceu o aporte de carbono orgânico total abaixo das demais áreas em reflorestamento, possivelmente devido à menor presença de raízes observada nessa camada. Para as demais áreas, angico (2), paricá (3) e mata nativa (4) não houve diferença estatística. AGRARIAN ACADEMY, Centro Científico Conhecer - Goiânia, v.2, n.04; p. 132015 
MOREIRA \& COSTA (2004) também observaram aumento de matéria orgânica no solo após reflorestamento em área desmatada na floresta amazônica, além do conteúdo da biomassa microbiana.

Para BAYER et al. (2000), a utilização de diferentes manejos poderá favorecer a ocorrência de elevadas taxas de decomposição da matéria orgânica do solo. Em estudos realizados por WENDLING et al. (2005) e SILVA et al. (2007), observaram correlação positiva entre 0 teor de carbono orgânico e o diâmetro médio dos agregados, evidenciando a importância do carbono orgânico para o solo. Na Figura 2 é demonstrado o teste de média para a massa específica do solo nas quatro áreas avaliadas em diferentes camadas.

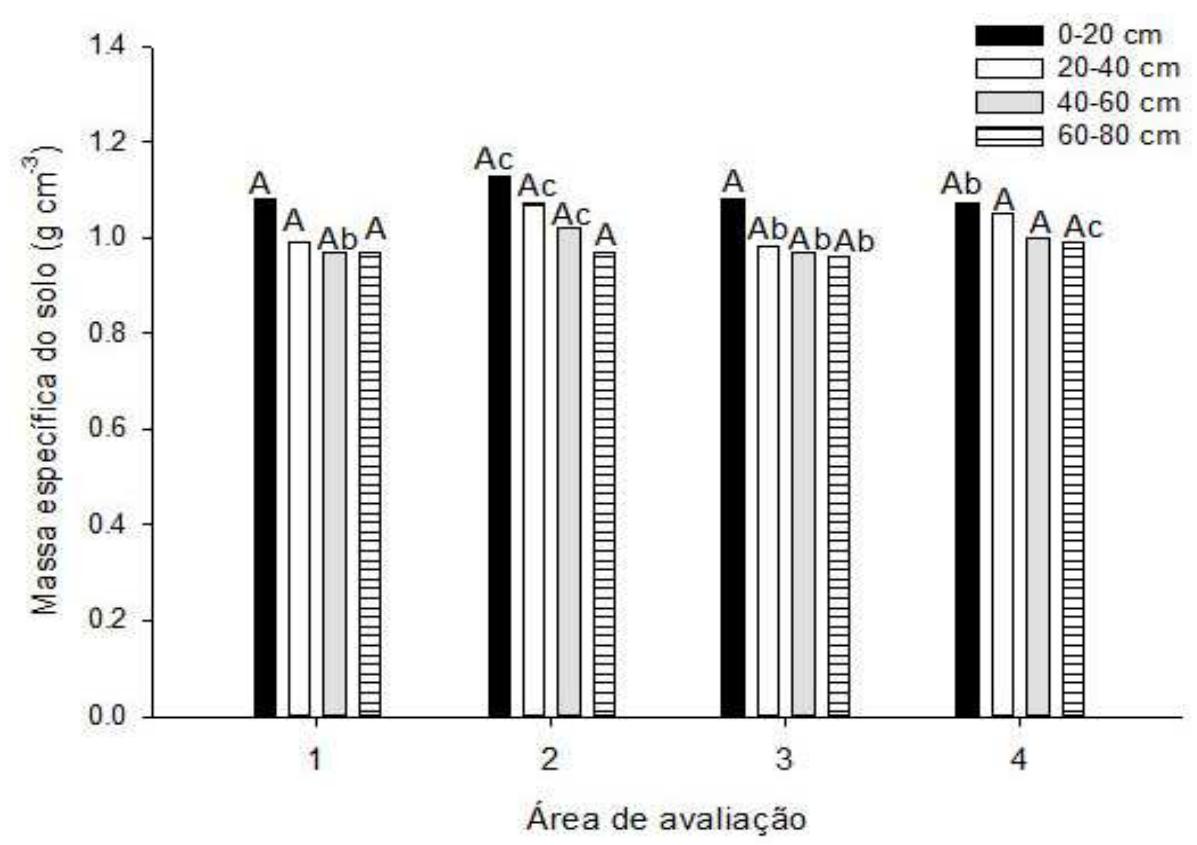

FIGURA 2. Massa específica do solo para as quatro áreas avaliadas, sendo: 1 - pastagem; 2 - angico; 3 - paricá; e 4 - mata nativa.

Médias seguidas da mesma letra maiúscula e minúscula entre colunas e entre áreas não diferem entre si ao nível de $p<0,05$ de probabilidade pelo teste de Kruskal-wallis.

Ao avaliar a camada de 0-20 cm, observou-se que houve diferença estatística apenas entre a área de angico (2) e mata nativa (4) para massa específica do solo, apresentando a mata nativa o menor valor, sendo de $1,07 \mathrm{~g} \mathrm{~cm}^{-3}$ para a manta nativa e de $1,13 \mathrm{~g} \mathrm{~cm}^{-3}$ para angico. As demais áreas, pastagem e paricá, apresentaram média de 1,08 e $1,08 \mathrm{~g} \mathrm{~cm}^{-3}$. A menor densidade encontrada para essa camada de solo na mata nativa pode ser explicado pelo maior teor de carbono orgânico total.

$\mathrm{Na}$ caracterização físico-hídrica de solos submetidos a diferentes manejos, ZWIRTES et al. (2011) observaram que em solos cultivados sob plantio direto, plantio convencional, mata nativa e pastagem perene cultivada apresentam maior densidade do solo do que solos de mata nativa, corroborando com o resultado deste trabalho.

$\mathrm{Na}$ camada de $20-40 \mathrm{~cm}$ houve diferença estatística entre as áreas de angico (2) e paricá (3), apresentando valores médios de 1,07 e $0,98 \mathrm{~g} \mathrm{~cm}^{-3}$, respectivamente. As demais áreas não diferiram estatisticamente entre si e entre as 
demais, apresentando média de $0,99 \mathrm{~g} \mathrm{~cm}^{-3}$ para pastagem e $1,05 \mathrm{~g} \mathrm{~cm}^{-3}$ para mata nativa.

Para a camada de 40-60 cm, a área de angico (2) diferiu das de pastagem (1) e paricá (3), apresentando valores médios de $1,02 \mathrm{~g} \mathrm{~cm}^{-3}$ para angico, $0,97 \mathrm{~g} \mathrm{~cm}^{-3}$ para pastagem e paricá. A área de mata nativa não diferiu entre as demais, apresentando valor médio de $1,00 \mathrm{~g} \mathrm{~cm}^{-3}$. Na camada de $60-80 \mathrm{~cm}$, a área de paricá apresentou menor massa específica do solo $\left(0,96 \mathrm{~g} \mathrm{~cm}^{-3}\right)$, diferindo estatisticamente da mata nativa, que apresentou maior valor entre as áreas, sendo de $0,99 \mathrm{~g} \mathrm{~cm}^{-3}$. As áreas de pastagem e angico não diferiram entre si e entre as demais áreas, ambas apresentando valor de $0,97 \mathrm{~g} \mathrm{~cm}^{-3}$.

Na Figura 3 é demonstrado o teste de média para a porosidade total do solo nas quatro áreas avaliadas em diferentes camadas.

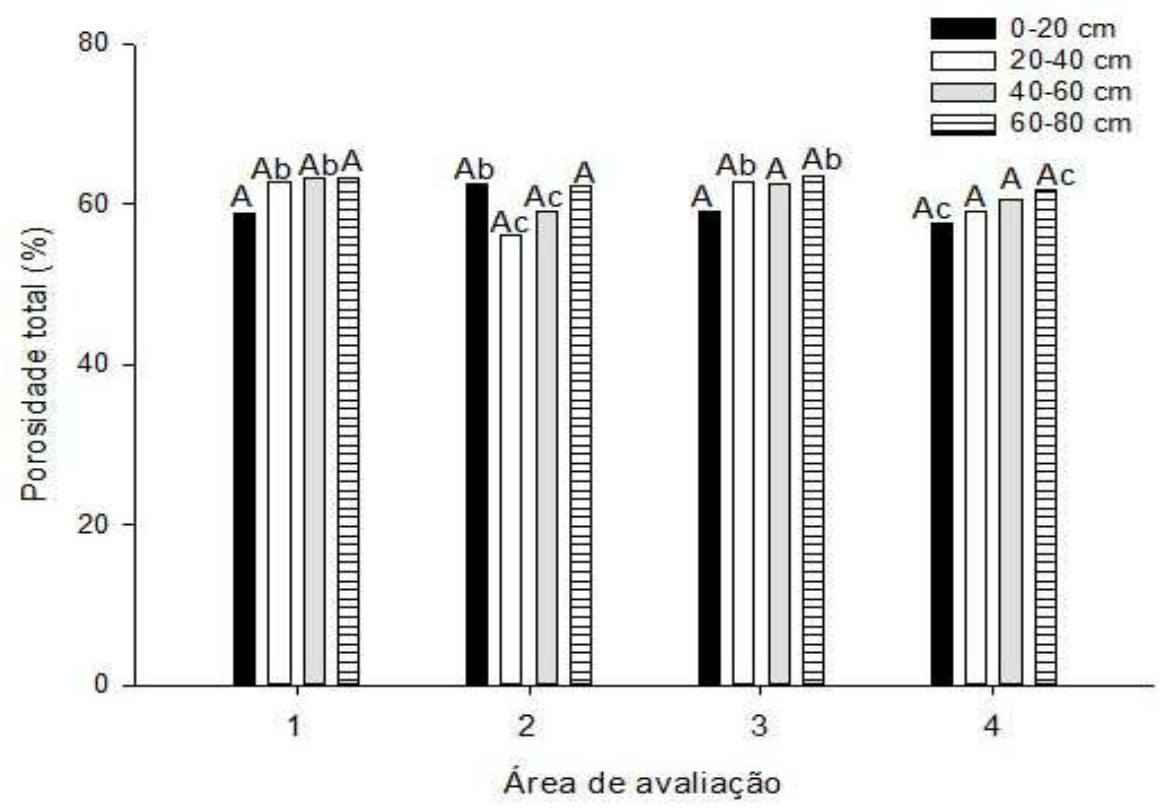

FIGURA 3. Porosidade total do solo para as quatro áreas avaliadas, sendo: 1 - pastagem; 2 - angico; 3 - paricá; e 4 - mata nativa.

Médias seguidas da mesma letra maiúscula e minúscula entre colunas e entre áreas não diferem entre si ao nível de $p<0,05$ de probabilidade pelo teste de Kruskalwallis.

Observa-se que a porosidade total do solo na camada de $0-20 \mathrm{~cm}$ foi estatisticamente diferente apenas entre as áreas de angico (2) e mata nativa (4), obtendo valores médios de 62,51 e $57,64 \%$, respectivamente. Para as demais áreas não houve diferença estatística, apresentando valores médios de 58,92\% para pastagem e 59,03\% para paricá.

Ao avaliar a camada de $20-40 \mathrm{~cm}$, observa-se que as áreas de pastagem (1) e paricá (3) foram estatisticamente iguais, diferindo da área de angico (2). Os valores médios de porosidade total para essa camada foram de $62,63 \%$ para pastagem, de $62,62 \%$ para paricá e de $56,19 \%$ para angico. A área de mata nativa não diferiu das demais, apresentando valor médio de 59,11\%. Na camada de 40-60 cm houve diferença estatística apenas entre a área de pastagem (1) e angico (2), apresentando valores médios de 63,26 e 59,13\%, respectivamente. Para as áreas de paricá (3) e mata nativa (4) não houve diferença estatística, apresentando valor médio de 62,38 e $61,63 \%$, respectivamente. 
Para a camada de $60-80 \mathrm{~cm}$, nota-se que as áreas de paricá (3) e mata nativa (4) diferiram estatisticamente, apresentando valores médios de 63,45 e $61,63 \%$. A maior porosidade total na área de paricá é explicada pelo menor valor de massa específica do solo, já demonstrado na Figura 2. As demais áreas não diferiram estatisticamente, apresentando valores médios de 63,12 e 62,36\% para pastagem e angico, respectivamente.

$\mathrm{Na}$ Tabela 1 é apresentado o teste de média para a capacidade de água disponível (CAD), cujo valor foi determinado pelo conteúdo de água do solo disponível entre a capacidade de campo $(0,01 \mathrm{MPa})$ e o ponto de murcha permanente (1,5 MPa).

TABELA 1. Capacidade de água disponível (CAD) para quatro camadas nas tensões de 0,01 MPa e 1,5 MPa, capacidade de campo (CC) e ponto de murcha permanente (PMP), respectivamente, para diferentes coberturas de solo na floresta piloto

\begin{tabular}{|c|c|c|c|}
\hline \multicolumn{4}{|c|}{$0-20 \mathrm{~cm}$} \\
\hline Área & CC & PMP & $C A D$ \\
\hline $\begin{array}{l}\text { Pastagem } \\
\text { Angico } \\
\text { Paricá } \\
\text { Mata nativa } \\
\end{array}$ & $\begin{array}{l}17,26 \\
16,26 \\
17,05 \\
17,53 \\
\end{array}$ & $\begin{array}{c}10,08 \\
9,90 \\
11,29 \\
10,86 \\
\end{array}$ & $\begin{array}{c}7,18 \mathrm{Ab} \\
6,36 \mathrm{~A} \\
5,76 \mathrm{Ac} \\
6,67 \mathrm{~A} \\
\end{array}$ \\
\hline \multicolumn{4}{|c|}{$20-40 \mathrm{~cm}$} \\
\hline $\begin{array}{l}\text { Pastagem } \\
\text { Angico } \\
\text { Paricá } \\
\text { Mata nativa } \\
\end{array}$ & $\begin{array}{l}18,89 \\
18,08 \\
19,83 \\
19,13 \\
\end{array}$ & $\begin{array}{l}13,72 \\
12,56 \\
14,69 \\
12,98 \\
\end{array}$ & $\begin{array}{l}5,17 \mathrm{~A} \\
5,52 \mathrm{~A} \\
5,14 \mathrm{Ac} \\
6,15 \mathrm{Ab} \\
\end{array}$ \\
\hline \multicolumn{4}{|c|}{$40-60 \mathrm{~cm}$} \\
\hline $\begin{array}{l}\text { Pastagem } \\
\text { Angico } \\
\text { Paricá } \\
\text { Mata nativa } \\
\end{array}$ & $\begin{array}{l}21,73 \\
20,33 \\
21,33 \\
20,72 \\
\end{array}$ & $\begin{array}{l}15,96 \\
15,33 \\
15,35 \\
14,99 \\
\end{array}$ & $\begin{array}{c}5,77 \mathrm{Ab} \\
5,00 \mathrm{Ac} \\
5,98 \mathrm{Ab} \\
5,73 \mathrm{~A}\end{array}$ \\
\hline \multicolumn{4}{|c|}{$60-80 \mathrm{~cm}$} \\
\hline $\begin{array}{c}\text { Pastagem } \\
\text { Angico } \\
\text { Paricá } \\
\text { Mata nativa } \\
\end{array}$ & $\begin{array}{l}24,35 \\
21,45 \\
21,64 \\
23,39 \\
\end{array}$ & $\begin{array}{l}17,60 \\
15,79 \\
17,19 \\
16,42 \\
\end{array}$ & $\begin{array}{l}6,75 \mathrm{~A} \\
5,66 \mathrm{~A} \\
4,45 \mathrm{Ac} \\
6,97 \mathrm{Ab} \\
\end{array}$ \\
\hline
\end{tabular}

Médias seguidas da mesma letra maiúscula e minúscula entre linhas não diferem entre si ao nível de $\mathrm{p}<0,05$ de probabilidade pelo teste de Kruskal-wallis.

Observou-se que na camada de $0-20 \mathrm{~cm}$ de camada houve diferença estatística, para a capacidade de água disponível, apenas entre as áreas de pastagem e paricá, obtendo média de $7,18 \%$ para pastagem e de 5,76\% para paricá. O melhor resultado encontrado para a área de pastagem, nesta camada de solo, pode ser explicado pela maior porosidade total já demonstrado na Tabela 1. Para as demais áreas não houve diferença estatística. 
Para a camada de $20-40 \mathrm{~cm}$, nota-se que a capacidade de água disponível foi estatisticamente diferente apenas para a área de paricá e manta nativa, obtendo média de 5,14 e 6,15\%, respectivamente. Essa maior retenção de água pode ser explicada pelo maior teor de carbono orgânico total nesta camada de solo em mata nativa. Para as demais áreas não houve diferença estatística. Para a camada de 40$60 \mathrm{~cm}$ a área de angico diferiu da de pastagem e paricá, obtendo média de 5,0\% para angico, 5,77\% para pastagem e 5,98\% para paricá. A área de mata não diferiu das demais.

$\mathrm{Na}$ camada de $60-80 \mathrm{~cm}$ a área de paricá diferiu da mata nativa, obtendo média de $4,45 \%$ contra $6,97 \%$ da mata nativa. Para esta camada de solo, provavelmente o maior teor de argila e carbono orgânico total da área de pastagem foi determinante na maior retenção de água, conforme demonstrado na Tabela 1. Para as demais áreas não houve diferença estatística.

$\mathrm{Na}$ Tabela 2, são apresentadas as correlações de Pearson entre massa específica, carbono orgânico total, teor de argila, porosidade total do solo e a retenção de água na capacidade de campo e no ponto de murcha permanente.

TABELA 2. Correlações de Pearson entre a retenção de água na capacidade de campo (CC) e ponto de murcha permanente (PMP) e os teores de massa específica $(\mathrm{Da})$, carbono orgânico total $(\mathrm{COT})$, teor de argila, e porosidade total do solo

\begin{tabular}{ccccc}
\hline & Da & COT & Argila & PT \\
\hline CC & & Pastagem & & \\
\hline PMP & $-0,80^{* *}$ & $-0,89^{* *}$ & $0,93^{* *}$ & $0,77^{* *}$ \\
\hline CC & $-1,00^{* *}$ & $-0,99^{* *}$ & $0,95^{* *}$ & $0,92^{* *}$ \\
\hline PMP & Angico & & \\
\hline CC & $-1,00^{* *}$ & $-0,91^{* *}$ & $0,97^{* *}$ & $0,98^{* *}$ \\
PMP & $-0,99^{* *}$ & $-0,95^{* *}$ & $0,93^{* *}$ & $1,00^{* *}$ \\
\hline CC & $-0,97^{* *}$ & Paricá & & \\
\hline PMP & $-0,96^{* *}$ & $-1,00^{* *}$ & $1,00^{* *}$ & $0,94^{* *}$ \\
\hline & $-0,97^{* *}$ & $0,98^{* *}$ & $0,97^{* *}$ \\
\hline & $-0,99^{* *}$ & Mata nativa & & \\
\hline & $-1,00^{* *}$ & $-0,99^{* *}$ & $0,97^{* *}$ & $0,98^{* *}$ \\
\hline
\end{tabular}

${ }^{* *}$ Significativo a $p<0,01$.

A matéria orgânica e a massa específica do solo não tiveram correlação positiva com a retenção de água na capacidade de campo e no ponto de murcha permanente. CENTURION \& ANDRIOLI (2000) e BEUTLER et al. (2002) também não verificaram participação efetiva da matéria orgânica na retenção de água.

Contudo, o teor de argila e a porosidade total nas diferentes camadas de solo e áreas apresentou correlação positiva e significativa com a retenção de água no solo. O efeito da argila no aumento da retenção de água no solo foi confirmando por DEMATTÊ (1988).

A maior retenção de água na capacidade de campo e ponto de murcha permanente em camada, provavelmente, deveu-se à mineralogia oxídica da fração argila, que segundo FERREIRA et al. (1999), promove a formação de microagregados arredondados com menos de $1 \mathrm{~mm}$, formando um aspecto maciço 
poroso "in situ", favorecendo maior proporção de poros grandes e uma menor densidade do solo. De acordo com REICHARDT \& TIMM (2004), quando o conteúdo de água no solo se encontra próximo à saturação, a curva de retenção depende do arranjo poroso do solo. No entanto, em tensões maiores, com redução no conteúdo de água do solo, os fatores geométricos passam a ter menor importância, dando destaque para a textura do solo, como a fração argila.

Os maiores teores de carbono orgânico da camada de solo de $0-20 \mathrm{~cm}$ nas quatro áreas estudadas (pastagem: $19 \mathrm{~g} \mathrm{~kg}^{-1}$; angico: $16,4 \mathrm{~g} \mathrm{~kg}^{-1}$; paricá: $16,6 \mathrm{~g} \mathrm{~kg}^{-1}$; mata: $19,1 \mathrm{~g} \mathrm{~kg}^{-1}$ ) não foi determinante na retenção de água no solo, uma vez que a camada superficial do solo obteve menor retenção de água na capacidade de campo e ponto de murcha permanente. BEUTLER et al. (2002), observaram que a quantidade de matéria orgânica teve pouca influência na retenção de água no solo cultivado com algodão e cana-de-açúcar.

\section{CONCLUSÕES}

O teor de carbono orgânico total foi maior dos 60 aos $80 \mathrm{~cm}$ de camada de solo para as áreas com plantio de angico, paricá e mata nativa, em relação à área de pastagem.

O teor de argila e a porosidade total apresentaram efeito positivo na retenção de água no solo, em todas as camadas, em relação ao carbono orgânico total e massa específica do solo.

\section{REFERÊNCIAS}

BAYER, C.; MIELNICZUK, J.; AMADO, T. J. C.; MARTIN-NETO, L.; FERNANDES, S. A. Organic matter storage in a sandy loam Acrisol affected by tillage and cropping systems in southern Brazil. Soil and Tillage Research, v. 54, n. 1, p. 101-109, 2000.

BEUTLER, A, N,; CENTURION, J, F,; SOUZA, Z, M,; ANDRIOLI, I,; ROQUE, C, G, Retenção de água em dois tipos de Latossolos sob diferentes usos, Revista Brasileira de Ciência do Solo, v. 26, n. 3, p,829-834, 2002.

BROWN, S.; LUGO, A. E. Rehabilitation of tropical lands: a key sustaining development. Restoration ecology, v. 2, p. 97-111, 1994.

CENTURION, J. F.; BEUTLER, A. N.; SOUZA, A. M. Physical attributes of kaolinitic and oxidic oxisols resulting from different usage systems. Brazilian Archives of Biology and Technology, v. 47, n. 5, p. 725-732, 2004.

CENTURION, J. F.; ANDRIOLI, I. Regime hídrico de alguns solos de Jaboticabal. Revista Brasileira de Ciência do Solo, v. 24, p. 701-709, 2000.

CHRISTOPHER, S. F.; LAL, R. Nitrogen Management affects carbon sequestration in north American cropland soils. Critical Reviews in Plant Sciences, v. 26, p. 4564, 2007.

DEMATTÉ, J. L. I. Manejo de solos ácidos dos trópicos úmidos - região amazônica. Campinas: Fundação Cargill, 1988. 215p. 
EMPRESA BRASILEIRA DE PESQUISA AGROPECUÁRIA - EMBRAPA. Sistema Brasileiro de Classificação de Solos. 3 ed. Brasília: Ministério da Agricultura e do Abastecimento, 2013. 353p.

FERREIRA, M. M.; FERNANDES, B.; CURI, N. Mineralogia da fração argila e estrutura de Latossolos da região sudeste do Brasil. Revista Brasileira de Ciência do Solo, v. 23, p. 507-514, 1999.

GÓES, G. B.; GREGGO, T. C.; CENTURION, J. F.; BEUTLER, A. N., ANDRIOLI, I. Efeito do cultivo da cana-de-açúcar na estabilidade de agregados e na condutividade hidráulica do solo. Irriga, v. 10, n. 2, p. 116-122, 2005.

LUCA, E. F. de; FELLER, C.; CERRI, C. C.; BARTHÈS, B.; CHAPLOT, V.; CAMPOS, D. C.; MANECHINI, C. Avaliação de atributos físicos e estoque de carbono e nitrogênio em solos com queima e sem queima de canavial. Revista Brasileira de Ciência do Solo, v. 32, n. 2, p. 789-800, 2008.

MACHADO, J. L.; TORMENA, C. A.; FIDALSKI, J.; SCAPIM, C. A. Inter-relações entre as propriedades físicas e os coeficientes da curva de retenção de água de um latossolo sob diferentes sistemas de uso. Revista Brasileira de Ciência do Solo, v. 32, p. 495-502, 2008.

MOREIRA, A.; COSTA, D. G. Dinâmica da matéria orgânica na recuperação de clareiras da floresta amazônica. Pesquisa Agropecuária Brasileira, v. 39, n. 10, p. 1013-1019, 2004.

PORTELA, J, C,; LIBARDI, P, L,; VAN LIER, Q, J, Retenção de água em solo sob diferentes usos no ecossistema tabuleiros costeiros, Revista Brasileira de Engenharia Agrícola e Ambiental, v, 5, p, 49-54, 2001.

REICHARDT, K.; TIMM, L. C. Solo, Planta e Atmosfera: Conceitos, Processos e Aplicações. São Paulo: Editora Manole, 2004. 478p.

ROZANE, D. E.; CENTURION, J. F.; ROMUALDO, L. M.; TANIGUCHI, C. A. K.; TRABUCO, M.; ALVES, A. U. Estoque de carbono e estabilidade de agregados de um latossolo vermelho distrófico, sob diferentes manejos. Bioscience Journal, v. 26, n. 1, p. 24-32, 2010.

SILVA JUNIOR, M. C.; SACARANO, F. R.; SOUZA CARDEL, F. Regeneration of in Atlantic Forest formation in the under store of a Euclyptus grandis plantation in southeastern Brazil. Journal Tropical Ecology, v. 11, p. 147-152, 1995.

SILVA, A. J. N.; RIBEIRO, M. R.; CARVALHO, F. G.; SILVA, V. N.; SILVA, L. E. S. F. Impact of sugarcane cultivation on soil carbon fractions, consistence limits and aggregate stability of a Yellow Latossol in Northeast Brazil. Soil and Tillage Research, v. 95, n. 4, p.420-424, 2007.

SILVA, J. R. L. da; MONTENEGRO, A. A.; SANTOS, T. E. M. dos. Caracterização física e hidráulica de solos em bacias experimentais do semiárido brasileiro, sob 
manejo conservacionista. Revista Brasileira de Engenharia Agrícola e Ambiental, v. 16, n.1, p. 27-36, 2012.

WENDLING, B.; JUCKSON, I.; MENDONÇA, E. S.; NEVES, J. C. L. Carbono orgânico e estabilidade de agregados de um Latossolo Vermelho sob diferentes manejos. Pesquisa Agropecuária Brasileira, v. 40, n. 5, p. 487-494, 2005.

ZWIRTES, A. L.; SPOHR, R. B.; BARONIO, C. A.; ROHR, M. R. Caracterização físico-hídrica de solos submetidos a diferentes manejos. Revista Brasileira de Tecnologia Aplicada nas Ciências Agrárias, v. 4, n. 3, p. 51-66, 2011. 